\title{
O BAIRRO NA PEQUENA CIDADE: PARA ALÉM DA IDENTIDADE, O CONFLITO
}

\section{NEIGHBORHOOD IN SMALL CITIES: BESIDES IDENTITY, THE CONFLICT}

\author{
Vicente de Paulo da Silva1 \\ ${ }^{1}$ Universidade Federal de Uberlândia (UFU), Uberlândia, MG, Brasil
}

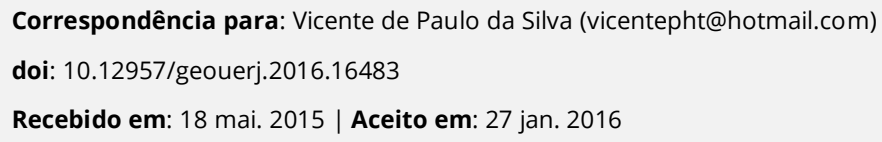

\section{RESUMO}

Este artigo visa a discutir as relações de convivência em pequenas cidades, a partir da construção, nos diferentes sentidos, denominada bairro e como essa complexa construção, por vezes, exerce importante papel na vida de seus moradores os quais se identificam e se reconhecem a partir desses espaços. Além disso, o simples fato de viver num determinado bairro pode contribuir para isolar e estigmatizar moradores de outros bairros quer seja por questões estritamente econômicas ou, de forma menos compreensível, pelo fato de o indivíduo ser um novo morador vindo de outro bairro ou de outra cidade. Os conflitos que se estabelecem são de diferentes ordens, mas não menos violentos que situações vividas em cidades maiores. A não aceitação de um novo morador se constitui em uma agressão ao direito de ir e vir de todo cidadão e remete à questão colocada por Armando Correa da Silva (1986), quando nos referimos ao bairro ou à cidade, "de quem é o pedaço?".

Palavras-chave: Pequenas cidades; Bairro; Conflitos.

\section{ABSTRACT}

This paper discusses the coexistence relationships in small cities. It starts from a construction, the neighborhood, in its different senses and how that complex construction, sometimes, become an important space to people living there because they identifies and recognizes the resident, besides contributing to isolate and stigmatize other residents considered different, both for economical or, in a less comprehensible way, for the individual being a new coming resident of another neighborhood or another city. The settle down conflicts are of different orders, but not less violent than situations lived in larger cities. The non acceptance of a new resident is an aggression to the right to go and come of every citizen and sends to a question told by Armando Correa da Silva (1986), when we refer to the neighborhood or the city, "who's the place's owner?

Keywords: Small cities; neighborhood; conflicts.

\section{INTRODUÇÃO}

As tramas que se desenrolam no bairro são demasiadamente complexas. Primeiramente, vale pensar o significado dessa porção delimitada na cidade e, posteriormente, buscar o entendimento das relações entre seus moradores, entre esses e os moradores de outros bairros e desses com o próprio bairro. Uma área delimitada, mas não, necessariamente, cercada, com limites bem definidos na planta da cidade. Espacialmente contínuos. Uma continuidade que, por vezes, faz perder o limite entre bairros para aquele que vem de fora, mas não para aquele morador que vive nesse local as suas relações cotidianas. 
O morador se identifica com seu bairro e nesse processo acaba por identificar também os outros moradores. A situação se complica quando moradores de outros bairros entram no espaço do outro e aí passam a ser também reconhecidos, mas como o diferente, o de fora, o estranho. 0 conflito se estabelece e se torna mais complexo, principalmente quando o bairro apresenta características que mais revelam as condições de seus moradores, sejam elas econômicas ou socioculturais.

É a partir daí que se pode falar em bairros ricos e bairros pobres. A diferença mais clara entre eles pode ser percebida na paisagem, ou seja, a estrutura do bairro revela a sua condição e, consequentemente, a de seu morador. Um sentimento de repulsa pelo outro, as vezes por medo, as vezes por desconhecimento mesmo da realidade, surge em função dessa diferença.

Essa situação é mais claramente observada quando se tratam de cidades menores. Entretanto, é preciso pensar como Elias (2000, p.20) quando diz

\footnotetext{
O uso de uma pequena unidade social como foco de investigação de problemas encontráveis numa grande variedade de unidades sociais, maiores e mais diferenciadas, possibilita a exploração desses problemas com uma minúcia considerável - microscopicamente, por assim dizer. Pode-se construir um modelo explicativo, em pequena escala, da figuração que se acredita ser universal - um modelo pronto para ser testado, ampliado e, se necessário, revisto através da investigação de figurações correlatas em maior escala.
}

Neste sentido propomos esta reflexão sobre o bairro na pequena cidade, entendendo, conforme a citação anterior que o mesmo pode acontecer também nas grandes cidades, mas é nessa escala, a da pequena cidade, que as coisas se apresentam com maior nitidez. Assim, partimos da experiência observada durante a realização de nossa pós graduação, em nível de doutorado, quando um conflito se estabeleceu entre moradores de bairros diferentes. Observamos que os moradores de determinados bairros passaram a estigmatizar outros com argumentos muitas vezes infundados.

Foi durante as nossas idas e vindas em trabalhos de campo que as coisas começaram a fazer certo sentido, não que isso justifique o conflito, mas, nossa empreitada foi revelando o que de fato estava por trás dessa discriminação de moradores de bairros mais pobres por moradores de bairros considerados mais ricos, como expomos ao longo desse trabalho. Para entender melhor o conflito achamos por bem 
iniciar buscando a definição de bairro, o significado dessa construção e, depois, refletir sobre a condição de diferença entre moradores e, principalmente, a forma como esses moradores vêem e tratam o que vem de fora, ou seja, aquele que não é morador do bairro que, por vezes, pode ser só um visitante, um viajante.

\section{A Construção Histórico-Simbólica do Bairro}

O que é e o que significa essa parte delimitada da cidade chamada bairro? Por um lado, trata-se da divisão administrativa da cidade. Por outro, e de forma mais complexa, é uma construção histórica e simbólica, caracterizada por uma conotação afetiva que é interiorizada por seus moradores. É um fator de identidade entre morador e lugar e de identificação entre os membros da comunidade. Além disso, sua construção desperta um sentimento quase "patriótico" por essa porção delimitada. Numa análise sócio-histórica em "Artes de Fazer - Morar, Cozinhar", Mayol (1998, p. 40) oferece uma contribuição à definição de bairro, em seu estudo sobre as maneiras de morar na cidade: "o bairro é, quase por definição, um domínio do ambiente social, pois ele constitui para o usuário uma parcela conhecida do espaço urbano na qual positiva ou negativamente, ele se sente reconhecido". Ser reconhecido é, portanto, o princípio da identificação entre o morador e o bairro.

Na definição de Mayol, o bairro é entendido como espaço público. Mas, na forma de apropriação e no seu uso, muitas vezes ele é confundido com um espaço privado: "o bairro é, por conseguinte, no sentido forte do termo, um objeto de consumo do qual se apropria o usuário no modo de privatização do espaço público"(op. cit., p.45).

Todavia, esse autor dirá que a noção de bairro é dinâmica e necessita de uma progressiva aprendizagem que evolui desde a repetição do engajamento do corpo do usuário no espaço público até aí exercer uma apropriação: "o bairro constitui o termo médio de uma dialética existencial entre um dentro e um fora. E é na tensão entre esses dois termos, um dentro e um fora, que vai aos poucos se tornando o prolongamento de um dentro, que se efetua a apropriação do espaço" (MAYOL, 1998, p.42). 
Neste sentido, Mayol ressalta que o bairro poderia ser definido como um prolongamento da habitação que não constituiria propriamente uma superfície urbana transparente para todos, nem seria estatisticamente mensurável, mas, acima de tudo, o bairro seria "a possibilidade oferecida a cada um de se inscrever na cidade um sem-número de trajetórias cujo núcleo irredutível continua sendo sempre a esfera do privado" (MAYOL, 1998, p.42).

Uma visão diferente é apresentada por Lamas, ao trazer a contribuição da arquitetura para a compreensão do conceito de bairro. Para esse autor, o bairro constitui uma dimensão espacial na morfologia urbana:

É a partir desta dimensão, ou escala, que existe verdadeiramente a área urbana, a cidade ou parte dela. Pressupõe uma estrutura de ruas, praças ou formas de escalas inferiores. Corresponde numa cidade aos bairros, às partes homogêneas identificáveis e pode englobar a totalidade da vila, aldeia, ou da própria cidade (LAMAS, 1992, p.74).

Assim, na visão desse autor, o espaço pode ser dividido em partes identificáveis - os recortes - dos quais os bairros podem servir de exemplo e que formam a cidade. Portanto, a compreensão sobre as formas urbanas pode ser posta em diferentes níveis, de acordo com o interesse da leitura e da própria concepção que se tem dessas.

De acordo com Lamas (op. cit.) a escala da rua representa a menor unidade ou porção do espaço urbano, enquanto a escala do bairro, com forma própria, aparece acima dessa dimensão. Por último, o autor discorre sobre a dimensão territorial identificada como a escala da cidade que é uma articulação dos diferentes bairros entre si.

No campo geográfico, Soares (1987) e Souza (1997) oferecem outras contribuições para compreensão do conceito de bairro. Para Soares, essa é uma noção de origem popular, que é marcadamente geográfica, rica e concreta. Para o habitante de uma cidade, que possui um sentimento coletivo da consciência de morar nesse ou naquele lugar, o bairro constitui um conjunto que tem significado e originalidade própria: 
Esse conhecimento global, que cada um tem de residir em determinado bairro, é fruto da coexistência de uma série de elementos, que lhe dão uma originalidade, uma individualidade, em meio aos outros bairros que o cercam. Cabe à geografia definir quais são esses elementos que, unidos, dão a um bairro sua feição característica (SOARES, 1987, p.105-106).

No entender de Soares, a cidade e os bairros são inseparáveis, e é pelo estudo deles que podemos conhecer o passado e o presente da cidade, além de podermos pressentir o seu futuro. Em sua concepção, "cidade e bairro são, pois, uma coisa só: não se pode conhecer uma cidade sem analisar os seus bairros, mas ao estudarmos um bairro temos sempre que ter em mente a cidade a que ele pertence" (SOARES, 1987, p.120).

A contribuição de Souza (1997) ao debate sobre o bairro leva-nos a uma tomada de consciência sobre o conceito de espaço social que, em sua definição, é, antes de tudo, um produto da transformação da natureza pelo trabalho social. O espaço é, assim, o palco das relações sociais que, como qualquer outra realidade social, não é uma entidade unicamente objetiva.

A materialidade do espaço em Souza é dotada de significações para cada indivíduo, e é também compartilhada por outros. Como palco material e objetivo das relações sociais, o espaço deve ser entendido como uma construção (inter) subjetiva: o bairro, a região, a terra natal ou a pátria.

Esses elementos constituem, segundo o autor, escalas nas quais podem ser encontrados exemplos de que esse suporte não é axiologicamente neutro. Neste sentido ele lembra que: “... na verdade é uma materialidade impregnada de valores, um referencial para a orientação quotidiana, um catalisador simbólico e afetivo (a rua onde se nasceu, morou ou mora, 'meu pedaço', 'meu bairro', 'minha região')" (SOUZA, 1997, p.23).

Retomamos os argumentos de Mayol (op. cit) para um entendimento do conceito de bairro que, de certa forma, contempla o conjunto das contribuições examinadas: trata-se da visão de que há um conteúdo social e cultural "segundo o qual o espaço urbano se torna não somente o objeto de um conhecimento, mas o lugar de um reconhecimento" (MAYOL, 1998, p. 45). 
E esse lugar de reconhecimento tem sido mais expressivo na escala do bairro, por reunir qualidades propiciadoras disso. Para o autor, o bairro é o lugar de conhecimento dos lugares, de trajetos cotidianos, relações de vizinhança (política), relações com os comerciantes (economia), sentimentos difusos de estar no próprio território (etologia).

O bairro é o lugar do encontro, mas é nele também que eclode a violência e é, na sua fisionomia, que se expressa a realidade caracterizadora daqueles que o habitam - bairro pobre, bairro rico ou bairro nobre. Às vezes, o fato de se habitar um determinado bairro é suficiente para identificar o cidadão, atribuindo-lhe características as mais diferentes e que se confundem com aquelas também atribuídas ao próprio bairro: sujo, violento, perigoso, rico, de classe média, ou limpo.

O discurso tende a homogeneizar, positiva ou negativamente, uma relação que é muito mais complexa, quando observamos os contrastes que caracterizam os bairros de uma cidade. Essa maneira de pensar já está arraigada entre as pessoas e tem surtido efeito a ponto de ser possível observar essa diferença social que se revela na visão que se tem do bairro, embora a aparência por si só não revele toda a realidade vivida pelos moradores.

Os moradores podem ser estigmatizados quando, no bairro, por exemplo, ocorrem elevados índices de delinquência. Os epítetos, ou estigmas, podem ocorrer tanto da parte de outros moradores do mesmo bairro, mas, de forma mais comum, por moradores de outros bairros. Por outro lado, um bairro assume também a característica de perigoso se nele habitam pessoas mais propensas ao crime, à violência. As características de ambos se fundem e, nesse processo, corre-se o risco de tanto um quanto outro perderem sua identidade.

Cotidianamente, o bairro é vivido, construído e apropriado por seus moradores. Porém, sua produção extrapola os limites da moradia. Ambos, morador e bairro, são inseridos numa relação de inclusão e, no seu oposto, de exclusão. Quanto ao morador, há um reconhecimento do "de dentro" assim como o reconhecimento do "de fora" do bairro pela sua posição de morador ou não. É essa relação a responsável pela produção - material e simbólica - do bairro. De lugar de moradia, de vizinhança, de 
cotidiano, um bairro pode passar a ser percebido como lugar de violência, de perigo, da distância que se deve manter se nele são percebidas tendências as essas atitudes ditas violentas. Tais condições denigrem com a imagem de um bairro em favor de outros em que ainda que se percebam as mesmas ações passam imagem de lugar seguro, de pouca ou quase nada de violência, lugar para se viver. Essa realidade expressa as contradições do discurso ao passo que cumprem um papel político de promover lugares à condição de maior valorização, inclusive, imobiliária.

Assim, com o apoio da proposta de Soares, torna-se possível compreender o passado e o presente de uma cidade por meio do estudo dos seus bairros. Entendemos, neste trabalho, que os principais elementos caracterizadores de cada bairro que compõe a cidade, são os seus moradores e a presença de equipamentos urbanos de maior importância entre as pessoas. Ainda assim, para resgatarmos a história da cidade de acordo com a trama que se desenvolve no bairro, é preciso que a ele sejam associados outros elementos, mediante os quais podemos compreender melhor a antagônica relação de inclusão e exclusão de moradores tanto no bairro quanto na cidade.

Nesse processo de reconhecimento, os dados estatísticos ajudam a compreender os acontecimentos, porém não são suficientes para explicá-los. Para entender melhor a realidade da cidade por meio da história dos bairros, acredita-se que o contato direto com os moradores constitua a melhor opção para complementar a leitura propiciada pelos dados estatísticos e para ultrapassar as primeiras impressões observadas durante uma pesquisa de campo, por exemplo.

Dados estatísticos podem indicar que em determinados bairros predominem segmentos de moradores cuja condição econômica se apresenta superior ou inferior aos outros moradores da cidade. Entretanto, se entendemos que a condição econômica não é quesito suficiente para que uma parte dos moradores estigmatize outra, então é in loco que podemos entender a dinâmica da relação que aí se estabelece.

\section{A Condição de Diferença na Vida Cotidiana em Sociedade}


O que significa dizer que uma pessoa é diferente porque veio de fora? Esse entendimento constitui o ponto de identificação do grupo que, principalmente numa pequena cidade, já experienciava o bairro, ou a própria cidade, que lhe dera significado e que, ao contrário dos novos moradores, carrega uma lembrança de um tempo vivido anteriormente na cidade.

Mas como explicar que essa experiência muitas vezes leva a um sentimento egoístico a ponto de ser refletida nas relações com os outros moradores, ou seja, os que chegaram de outros lugares, que não eram deste ou daquele bairro? Ou ainda, por que a estranheza simplesmente por constatar que um grupo vive em condições econômicas inferiores ao outro? Consideramos que o aspecto mais expressivo da divergência gerada a partir desse processo seja afetivo. Também aqui se aplicam os argumentos de Elias e Scotson (1994, p.78), de que "é difícil tornar essas tensões e conflitos mais suscetíveis ao controle humano enquanto há um nível elevado de afetividade no pensamento e percepção pertinentes a essa área, e um baixo nível de objetividade”.

Lepoutre (2001) identificou uma relação de estranhamento entre os adolescentes moradores dos grandes conjuntos habitacionais suburbanos. Esses adolescentes são diferentes do restante da sociedade, e essa diferença torna-se negativa ao criar deles, uma imagem, da mesma forma, negativa.

Segundo o autor, esses adolescentes constituem a facção pobre, desocupada, vítima do fracasso na escola, desempregada, violenta e delinquente, às vezes drogada e até criminosa ou revoltada, cheia de ódio e com tendência à sublevação. Em se tratando de grupos desprivilegiados, sujeitos aos efeitos negativos de uma concentração de renda, parece que o discurso pode ser aplicado de forma generalizada, uma vez que as características são sempre bastante semelhantes.

A condição de diferença leva a que pessoas sejam estigmatizadas no seio da sociedade. Essa diferença, muitas vezes, assume uma expressão de carência de bens materiais: "é como se a eles faltasse tudo que nos parece indispensável ao bom funcionamento de uma sociedade" (LEPOUTRE, 2001, p. 447). 
Acreditamos que os argumentos, possam contribuir para o entendimento do que acontece no bairro e, consequentemente, na cidade. Mas, também estamos convictos de que o conhecimento sobre novos moradores, por exemplo, não pode contentar-se unicamente com o fato de serem "de fora", ou que estejam em condições financeiras inferiores, para que se justifiquem os estigmas a que são submetidos. Essa forma de referir-se a novos moradores numa cidade, ou num bairro, nos permite entender que uma interpretação assim é, sobretudo, "fruto de um olhar exterior e distanciado", conforme palavras de Lepoutre.

O efeito desse olhar representa, por um lado, uma forma de exclusão social, em que os grupos considerados em condição inferior são taxados de marginais. Por outro lado, isso constitui também uma forma de controle social, pois define lugares em relação aos quais se deve evitar o contato. Se determinados bairros, por exemplo, não devem ser visitados por membros de outras áreas consideradas mais abastadas, também os moradores de áreas entendidas como sendo perigosas, não devem sair muito de seus territórios, uma vez que eles significam uma "ameaça à ordem".

Berger (2001, p.85) postula que "O ridículo e a difamação são instrumentos potentes de controle social em grupos primários de todas as espécies". A sujeição de pessoas a situações ridículas ou constrangedoras contribui, muitas vezes, para a mudança de comportamento e para a aceitação de normas impostas para o convívio harmônico em sociedade.

Todavia, o contrário também pode ocorrer. A exposição ao ridículo pode criar o sentimento de indignação, de ressentimento. Se isso ocorre, o desejo de vingança tornará o indivíduo propenso à violência. A reação pode ser imprevisível como atacar ou, conforme Berger, submeter ao opróbrio e ao ostracismo sistemáticos.

A estigmatização parece ser uma atitude comum onde existem grupos que convivem num mesmo espaço e em que um deles se apresenta em condições de inferioridade econômica e social. Por meio dessa estigmatização, expõem-se grupos, ou bairros inteiros, ao ridículo. O objetivo é sempre o mesmo: afirmar a superioridade de uns sobre outros. 
Um processo de estigmatização pode ser classificado como a expressão de uma relação de poder o qual pode, por vezes, ser dispendioso. Foucault (1995, p.217), mostra como muitas vezes o poder é exercido em diferentes sociedades de forma dispendiosa: "O poder, na verdade, não se exerce sem que custe alguma coisa". Há, ainda, um poder que alguns acreditam possuir e cujo exercício pode não custar tanto economicamente, mas pode apresentar efeitos sociais devastadores, principalmente entre os grupos menos privilegiados: é o caso do poder do olhar, das palavras, da discriminação, dentre outros.

O olhar, por exemplo, serve também como uma forma de controle social. Ninguém quer se expor ao ridículo. Sendo assim, é preferível enclausurar-se, não deixar os limites de seu território e não penetrar no território "dos outros". O olhar pode dizer à pessoa que ela é - ou está sendo - ridícula. Como uma forma de exercício do poder, o olhar não é tão dispendioso se for comparado ao custo de outras manifestações. Nesse sentido é pertinente a afirmação de Foucault quando diz que:

O olhar vai exigir muito pouca despesa. Sem necessitar de armas, violências físicas, coações materiais. Apenas um olhar. Um olhar que vigia e que cada um, sentindo-o pesar sobre si, acabará por interiorizar, a ponto de observar a si mesmo; sendo assim, cada um exercerá esta vigilância sobre e contra si mesmo. Fórmula maravilhosa: um poder contínuo e de custo afinal de contas irrisório (1995, p.218).

Nas pequenas cidades, o olhar pode exercer esse poder de forma ainda mais visível e constitui uma forma de controle social, que provoca os efeitos morais desejados. Não é bom estar em um lugar onde não somos aceitos. Muitas vezes um olhar é suficiente para exprimir uma condição de rejeição.

A superioridade com que um grupo manifesta sua condição diante de outros grupos é um exemplo do que denominamos manifestação do poder. No intuito de se mostrar superior, um indivíduo ou um grupo é capaz de desfigurar culturalmente diversos grupos, minorias étnicas, manifestações populares, bairros ou, mesmo, cidades inteiras. 
Acreditamos que isso acontece em função de, quer seja na cidade, quer seja apenas no bairro, as condições de vida serem construídas de forma diferenciada. $\mathrm{O}$ acesso à moradia, ao lazer, aos lugares públicos, não se dá da mesma forma para todos. A diferença está aí e não no caráter das pessoas. A carência de bens materiais, de comida para os filhos, de educação, ou mesmo de um pouco de sorte, é confundida com o caráter das pessoas e passa a expor ao ridículo os cidadãos de uma mesma comunidade.

Finalmente, a reflexão de Peixoto (1995), sobre "O Olhar do Estrangeiro" parece revelar o sentido da estranheza entre as pessoas na comunidade. O estrangeiro, para esse autor, é definido como aquele que não é do lugar, aquele que acabou de chegar, ou que é mais pobre. Entretanto, o fato de ser estrangeiro, segundo o seu entendimento, não significa que a pessoa seja boa ou má, mas que há uma tendência, desse chamado estrangeiro, em ver as coisas com mais originalidade do que as pessoas que já possuem certo grau de experiência. Esse estrangeiro

\footnotetext{
É capaz de ver aquilo que os que estão lá não podem mais perceber... ele é capaz de olhar as coisas como se fosse pela primeira vez e de viver histórias originais. Todo um programa se delineia aí: livrar a paisagem da representação que se faz dela, retratar sem pensar em nada já visto antes. Contar histórias simples, respeitando os detalhes deixando as coisas aparecerem como são (PEIXOTO, 1995, p.363).
}

Esta tem sido talvez a condição mais expressiva e definidora do modo como vivem as pessoas que vão morar em lugar estranho para elas, mas que possuem toda uma história pregressa à sua chegada. Isso também ajuda a entender o estranhamento, ou as rixas que se desenrolam no dia-a-dia entre esse estrangeiro e os antigos moradores do lugar, da rua, do bairro, da cidade.

\section{O Conflito Entre os de Dentro e os de Fora}

O termo conflito é utilizado nesta discussão de acordo com o sentido registrado no Dicionário de Ciências Sociais: luta por valores e reivindicações de status, poder e recursos escassos, em que o objetivo dos oponentes consiste em neutralizar, lesionar ou eliminar os rivais. 
Este é o sentido que damos ao conflito entre antigos e novos moradores em um bairro ou entre bairros de uma pequena cidade, pois, nessas comunidades, o morador é mais conhecido, bastando apenas chegar para se saber que alguém é de fora.

Outra significação dada ao termo conflito é de Labourthe-Tolra e Warnier (1997) segundo a qual, na sua dinâmica, os conflitos podem tomar a forma de rixas, guerras ou mesmo de confrontos armados que, ao invés de se definirem como explosões anárquicas de violência, aparecem codificados como os outros fatos sociais.

Da mesma forma, esses autores argumentam que há diferenças entre conflitos intra e extra-societais. Os conflitos intra-societais, como dizem, são regulamentados em seus objetivos e meios, enquanto que nos conflitos extra-societais, como as guerras, que são um exemplo óbvio, tudo é permitido. Há um limite na sua existência em que o conflito assume o caráter de rixa e se define como intra-societal. É o estabelecimento dessa rixa entre os membros da comunidade que propomos discutir na sequencia.

Como se pode pensar na posição ocupada pelas pessoas (dentro ou fora) como definidora de um conflito? Dentro de quê? Fora de quê? Como estabelecer uma relação de acordo com essas definições? O caso tomado neste estudo se refere, de forma geral, às visões que as pessoas de uma comunidade têm sobre outras de grupos diferentes, seja religiosamente, seja socialmente, ou qualquer forma pela qual se possa expressar uma diferença.

Outros conflitos se estabelecem num mesmo espaço, tais como discriminação racial ou sexual e podem ser enquadrados numa outra discussão, que é a do preconceito social. Todavia, a característica desses preconceitos é também uma situação de diferenciação social entendida como negativa.

Queiroz (1973) observou um caso semelhante entre um grupo de vizinhança nos municípios de Itariri e de Rio das Pedras em São Paulo. O fenômeno foi chamado pela autora de "sentimento de localidade", cujo laço mais íntimo de coesão entre um grupo era o laço do parentesco. A "gente de fora" era formada por aquelas pessoas que estavam de fora dos laços de parentesco. Mesmo nesse caso, eram 
vítimas da discriminação pelo chamado "grupo de dentro". Havia, também, o caso em que a diferença residia, basicamente, no fato de um grupo de moradores ser novo no local - "a gente de fora". Segundo o entendimento do grupo "de dentro", a gente de fora habitava por acaso naquele lugar. A palavra "fora" designa ser "de outro lugar", portanto, diferente, mau:

\begin{abstract}
A 'gente de fora' é constituída em geral por camaradas que se instalam na região para trabalhar em sítios de japoneses, que mais e mais se espalham no município de Itariri; estes camaradas são considerados pelo pessoal de Rio das Pedras como 'pinguços' (bebedores de pinga) e briguentos (QUEIROZ, 1973, p.199).
\end{abstract}

Mendras (1978) também analisou situação semelhante em grupos de camponeses ou, como ele próprio ressalta, sociedades camponesas. Foi identificada, no grupo local, a sua rejeição ao grupo considerado de fora: "o dentro-do-grupo se afirma sempre contra o fora-do-grupo". A oposição entre os chamados grupos de dentro e os grupos de fora coloca os primeiros em condição de superioridade aos segundos. Essa condição é apontada, principalmente, quando se referem à moral das mulheres: "nossas mulheres são virtuosas e cheias de verguenza... mas nas aldeias vizinhas e, sobretudo nas cidades, elas são fáceis" (p.195).

Nesse caso, a aversão da comunidade camponesa é quanto a tudo que é exterior. O despertar desse sentimento já define a diferença "nós e eles" e, nessa condição, o "nós" exprime o lado bom, e o "eles", o lado mau. Nos estudos de Mendras, fica evidente a estratégia, no interior do grupo, de como se comportar diante da presença do "de fora". Isso faz reportar à questão da defesa. Por vezes, a defesa, expressa por um gesto de aparente aceitação, pode significar um ataque:

Receber bem o estrangeiro é também um meio de neutralizá-lo, caso sejam más as suas intenções: passe a soleira de minha porta diante de mim, para que eu possa ver suas costas e assim observar e controlar suas intenções melhor do que se eu passasse primeiro (MENDRAS, 1978, p.195).

A oposição entre grupos considerados diferentes, mesmo que a diferença seja mais em termos de tempo de residência no mesmo lugar, tem contribuído para a taxação da diferença como sendo, via de regra, má e perigosa. É preciso lembrar que cada situação tem suas especificidades e entender que não é possível generalizar os fatos. Muito embora Elias e Scotson (op. cit) já tenham dito que, resguardadas 
suas diferenças, "sob alguns aspectos, eles são iguais no mundo inteiro", torna-se então coerente perguntar: Que tipo de sentimento, hoje, é capaz de explicar essa atitude perante a diferença?

É com base em Relph (1980) que buscamos entender essa problemática. Seus argumentos mostram que no cerne dessa questão está o lugar. A identidade com um lugar soa como o sentimento mais forte, que se manifesta no morador estabelecido e produz a reação à possibilidade de compartilhar esse lugar com um novo morador.

Relph diz que a noção de identidade é fundamental na vida cotidiana. E um grupo responsável pela construção, material e simbólica, com anos de experiência no lugar, identifica-se com ele e chega ao extremo de sentir-se dono, não mais só daquilo que é seu de fato, mas, também, de tudo o que está à sua volta.

A partir da experiência com o lugar, as pessoas agem como se tivessem direitos sobre ele, chegando alguns a afirmarem: "isso aqui é nosso porque nós o construímos". Esse sentimento de posse reflete o apego ao lugar e, consequentemente, à necessidade de se organizar para defendê-lo das influências ou, simplesmente, da presença de outros.

Vale ressaltar, conforme Relph, que a identidade constitui um traço básico da nossa experiência de lugar e que, ao mesmo tempo, nossa experiência influencia e é influenciada por outras experiências. É em função da identidade com o lugar que se desenvolvem as formas de experiências insideness e outsideness, ou seja, de dentro e de fora do lugar. E, nesse sentido, tomamos novamente uma citação de Relph para esclarecer a diferenciação implícita na identidade com o lugar:

From the outside you look upon a place as a traveller might look upon a town from a distance; from the inside you experience a place, are surrounded by it and part of it. The inside - outside division thus presents itself as a simple but basic dualism, one that is fundamental in our experiences of lived-space one that provides the essence of place* (RELPH, 1980, p.49).

A fusão da história das pessoas com a história do lugar leva a que se desenvolva a reciprocidade entre ambos. Do mesmo modo, esse sentimento muitas vezes se confunde com a ideia de posse. Isso significa 
que não é num lugar qualquer que o novo morador está adentrando, mas num lugar histórico e simbolicamente construído por outros moradores.

A idéia de posse conduz à noção do particular, do privado. 0 que é privado é, portanto, condicionado à ideia de propriedade de alguém, ou de um grupo. Mas, na relação insideness - outsideness, o público muitas vezes assume o caráter de propriedade privada: "a nossa igreja, a nossa cidade, o nosso bairro, a nossa vista", enfim, soa como um tipo de propriedade, ainda que coletiva.

Assim como os muros ou a cerca encerram os limites de uma propriedade privada, também um bairro, uma rua, uma construção isolada, ou ainda, toda a área de uma cidade, entendidos como construção pública, são revestidos de limites. Muitas vezes, esses limites são imaginários e criam espécies de donos da rua, do bairro ou da cidade.

O grupo se reconhece e se aceita sem questionamentos. Às vezes também se estranha. Mas nenhuma estranheza é tão marcante quanto aquela referente a quem chega depois, o que veio "de fora". Imediatamente os laços de reconhecimento do grupo se aguçam, no afã de estranhamento do outro.

O morador mais antigo se sente parte do lugar da mesma forma que o lugar faz parte dele. Todavia, já foi dito por Relph, que a identidade com o lugar é mais do que um endereço ou um conjunto de aparências e quanto mais profundamente inside se estiver mais forte se torna esta identidade.

Com base no acima exposto, acreditamos que o sentimento de pertencimento ao lugar, ou a identidade com ele, possa estar paradoxalmente relacionado com as origens de tensões e rixas entre os moradores, na medida em que a presença de um estranho no lugar pode tornar vulneráveis as condições de segurança oferecidas por esse lugar, principalmente quando se refere às pequenas cidades.

Esse argumento se reforça com a fala de Relph, baseada em Lyndon (1962), ao sugerir que o lugar é a criação de um inside que é separado de um outside, e, neste sentido, esse autor propõe que o fato de estar dentro, ou inside, significa conhecer o lugar onde você está. Essa condição permite o reconhecimento propiciado pelo olhar de que alguém seja de fora, outside, estranho naquele lugar. 
Nesse sentido o lugar se revela como a diferença entre segurança e perigo, ou simplesmente o aqui e o lá, onde a pessoa não se sente ameaçada até que a presença de um diferente coloque em risco essa segurança.

\section{CONSIDERAÇÕES FINAIS}

O propósito deste trabalho foi refletir acerca da condição de diferença que marca, de forma positiva ou negativa, muitos moradores de pequenas cidades principalmente, ou mesmo de moradores de bairros diferentes dentro de uma mesma cidade. A elaboração do texto nos permite afirmar que a relação entre as pessoas pode ser mais ou menos conflituosa a depender do lugar social que cada um ocupa na sociedade, porém, esse lugar muitas vezes se confunde com o próprio lugar geográfico.

Isso acontece no nosso dia-a-dia e não é uma situação distante de cada um de nós. Basta observar que quando vamos a um lugar situado em bairro diferente daquele que moramos também sentimos uma estranheza em relação ao bairro e, por conseguinte, às pessoas do bairro. Isso talvez por sentirmos mais reconhecidos no bairro em que moramos, mas ainda assim essa é uma afirmação arriscada porque muitas vezes só somos reconhecidos nas imediações de nossa casa.

Nas pequenas cidades ainda podemos perceber certa relação de cordialidade entre as pessoas melhor que nas cidades de maior porte onde, atualmente, por vezes não conhecemos quem mora ao nosso lado. Isso nos leva também a pensar na definição do que vem a ser uma relação de vizinhança, pois, muitas vezes mantemos uma verdadeira relação de vizinhança com pessoas que moram distantes de nós e não necessariamente o vizinho é aquele que mora ao lado.

No Brasil o movimento de trabalhadores, intensificado pelo agronegócio, por exemplo, tem evidenciado essa atitude de moradores que se rebelam contra os que migram de um estado para outro, ou simplesmente de cidade em busca de trabalho. Normalmente esses trabalhadores mudam com a família ou sozinhos para as cidades onde são oferecidas tais vagas. Nesse processo, há o encontro de culturas diferentes e nesse encontro se estabelece o conflito. 
A depender da região onde se instalam, as pessoas que chegaram de fora, ou novos moradores, recebem uma alcunha que passa a representar o novo grupo. Há lugares na região sudeste do Brasil, por exemplo, em que o novo morador chegado do norte ou nordeste do país ou até mesmo de outras regiões, são conhecidos indistintamente por baianos ou nortistas, independentemente de terem migrado do nordeste ou do norte. Os termos, nesse caso, têm uma conotação negativa e servem para identificar os novos moradores diferenciando-os dos que já viviam no lugar. Em outros lugares, os migrantes do norte e nordeste recebem a alcunha de paraíba ou ceará. Por sua vez, os migrantes mineiros, principalmente de baixa renda, ou de condição cultural também diferenciada, são também apelidados de jecas, caipiras ou matutos.

Com isso percebe-se que na escala do bairro o lugar pode se manifestar em situações opostas para os indivíduos que o vivem, ou seja, apresentar um sentido de pertencimento ao morador mais antigo e, ao mesmo tempo, um sentido de estranheza ao novo morador que se percebe rejeitado pelos mais antigos. Esses sentimentos promovem as reações perante a presença de estranhos ao lugar e, com isso, promovem o conflito, inerente a todo ser humano. Isso talvez ocorra em escalas maiores, porém, é no bairro que seus efeitos se tornam mais nítidos.

\section{REFERÊNCIAS}

BERGER, P. L. Perspectivas sociológicas: uma visão humanística. 23 ed. Petrópolis: Vozes, 2001. 202 p.

ELIAS, N.; SCOTSON, J. L. Os estabelecidos e os outsiders: sociologia das relações de poder a partir de uma pequena comunidade. Rio de Janeiro: J. Zahar, 2000. 224 p.

FOUCAULT, M. O olho do poder. In: - Microfísica do poder. Organização, introdução e revisão técnica de Roberto Machado. Rio de Janeiro: Graal, 1995. p. 209-227.

LABURTHE-TOLRA, P.; WARNIER, J. Etnologia - antropologia. Petrópolis: Vozes, 1997. 469 p.

LAMAS, J. M. P. G. Morfologia urbana e desenho da cidade - textos universitários de ciências sociais e humanas. Lisboa: Fundação Calouste Gulbenkian, Junta Nacional de Investigação científica e tecnológica, 1992. p.63-117.

LEPOUTRE, David. A cultura adolescente de rua nos grandes conjuntos habitacionais suburbanos. In: MORIN, E. (org). A religação dos saberes. Rio de Janeiro: Bertrand Brasil, 2001, p. 447-453. 
MAYOL, P. Morar. In: CERTEAU, M. de; GIARD, L.; MAYOL, P. A invenção do cotidiano 2: morar, cozinhar. 2 ed. Petrópolis: Vozes, 1998. p. 35-185.

MENDRAS, H. Sociedades camponesas. Rio de Janeiro: Zahar, 1978. 265 p.

PEIXOTO, N. B. O olhar do estrangeiro. In: NOVAES, A (org). o olhar. São Paulo: Schwarcz Ltda, 1995. p. 361-365.

QUEIROZ, M. I. P. de. 0 campesinato brasileiro: ensaios sobre civilização e grupos rústicos no Brasil. Petrópolis: Vozes; São Paulo: EDUSP, 1973. 242 p.

RELPH, E. Place and placelessness. London: Pion Limeted, 1980. 156 p.

SOARES, M. T. de S. Bairros, bairros suburbanos, e subcentros. In: Cidade e Região. Rio de Janeiro: Secretaria Municipal de cultura - Departamento Geral de Documentação e Informação Cultural, 1987. p.121-133.

O conceito geográfico de bairro e sua exemplificação na cidade do Rio de Janeiro. In: Cidade e Região. Rio de Janeiro: Secretaria Municipal de cultura - Departamento Geral de Documentação e Informação Cultural, 1987. p.105-120.

SOUZA, M. L. de. Algumas notas sobre a importância do espaço para o desenvolvimento social. Território, v. 2, n. 3, p. 1333, jul./dez. 1997. 